\title{
El mundo de la vida del Departamento de Bellas Artes de la Universidad de Sonora
}

Por Emmy Ruvalcaba Olivarría

ruvalcabaemmy@gmail.com

Alumna de la Licenciatura en Música

Gloria Daniela López García

Danielopezg08@gmail.com

Abril María Nuñez Hernández

abrilnunezh@hotmail.com

Alumnas de la Licenciatura en Artes Escénicas,

opción Danza Contemporánea

La Universidad de Sonora se ha destacado por la producción de diversos eventos artísticos y culturales en cada ciclo escolar, en los cuales participan egresados/as, alumnos/as y maestros/as de las Licenciaturas en Artes Plásticas, Artes Escénicas (danza y actuación) y Música del Departamento de Bellas Artes. La cartelera ofrecida por nuestra comunidad en este semestre fue muy variada en eventos culturales y artísticos: conciertos, puestas en escena, cursos, festivales, conferencias y charlas, sobre ellos hablaremos a continuación.

La cartelera de eventos culturales comenzó el 29 de agosto del año en curso con un recital por parte de los alumnos/as de canto de la Licenciatura en Música, el evento formó parte de la serie de conciertos que se titulan Conciertos ConCiencia, los cuales son coordinados por el maestro Germán Mendoza, y llevados a cabo en el auditorio del Departamento de Física. El 9 de septiembre se celebró un concierto de Jazz, Boleros y Danzón en Está Cabral con Armando Carvajal y Juan Carlos Alfaro como artistas invitados. El 12 de septiembre se realizó la puesta en escena titulada "El beso que embaraza", dirigida por Oscar Fernández.

Los Viernes de concierto ya son una tradición en la Licenciatura en Música. Es un espacio para poner en práctica lo aprendido en las materias de desarrollo de habilidades en el instrumento. En esta ocasión fueron los alumnos del área de guitarra los que comenzaron la temporada el viernes 14 de septiembre.

El viernes 21 de septiembre se llevó a cabo, dentro de la agenda estatal de Escénicas, la obra de teatro experimental Ontología Mística, bajo la dirección de Gustavo Chaidez Herrera alumno de la Licenciatura en Artes Escénicas, opción actuación.

El concierto Alma mía se llevó a cabo los días 20, 21 y 26 de septiembre en la Sociedad Sonorense de Historia, el Kiosco del Arte y en el Centro Cultural Musas, respectivamente. La soprano Adriana Ponce, acompañada por el pianista Héctor Acosta, cantó árias de ópera las cuales eran introducidas por una breve explicación. A este evento acudieron aproximadamente ochenta personas, se celebró en la recepción del museo con motivos de su noveno aniversario.

El Festival Internacional de Cine en el Desierto tuvo lugar del 26 al 30 de septiembre en el teatro Emiliana de Zubeldía proyectándose Lo mejor que puedes hacer con tu vida y Antígona. Además, de un concurso de cortometrajes. Por otro lado, en ese mismo período, se presentó el grupo Aires de Son dirigido por Rafael Rodríguez y la obra de teatro Mujeres sin 


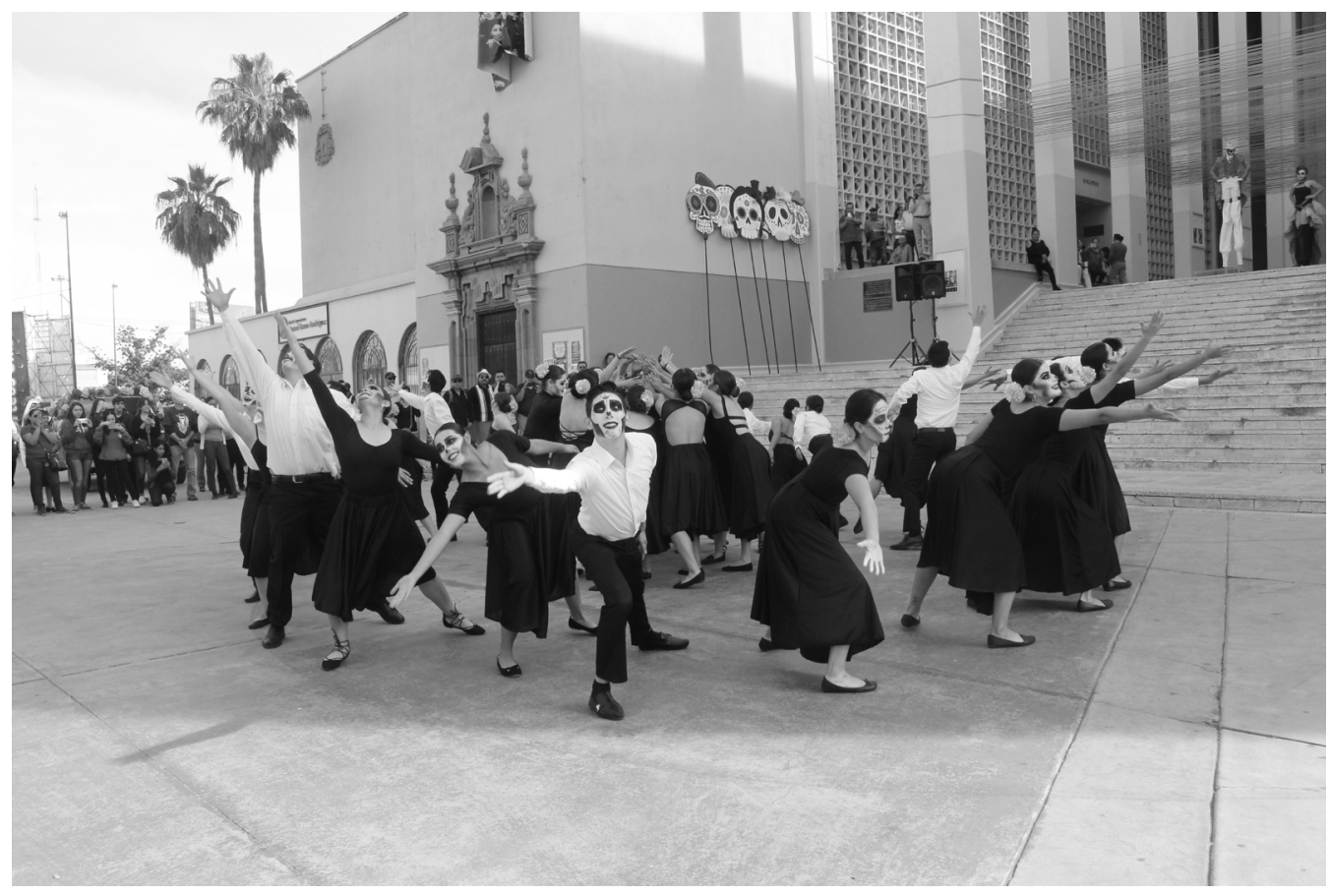

cuello bajo la dirección de Carlos Iván Córdova y además, un performance de Carlos Contreras, alumno de la Licenciatura en Artes Escénicas, opción actuación, titulada Cinco dosis de muerte en do para la libertad y el Viernes de concierto del área de composición.

El mes de octubre dio lugar a muchos eventos comenzando con el 13 Festival de Teatro Universitario organizado por la Licenciatura en Artes Escénicas, opción actuación, donde se presentaron diferentes puestas en escena, como lo fue El diccionario, obra de teatro presentada el 05 de octubre en el Foro Bellas Artes con la dirección de Enrique Singer. La Compañía Nacional de Teatro muestra el transcurso de vida de una mujer que ha sobrevivido la guerra civil de España y como su principal motivación de vida siempre fue el terminar su pequeño gran diccionario. El área de canto fue la encargada del Viernes de concierto del día 5 de octubre, al evento asistieron un total de cincuenta y dos personas y participaron alumnos/as de las profesoras Flor Herrera, Marybel Ferrales, Gabriela Copca y
Sarahí Salgado, los pianistas colaboradores fueron Héctor Acosta, Jaime Verdugo y Felizardo Andrade. En esta ocasión fue presentado también el trabajo realizado por los alumnos/as de la materia de Módulo de Consolidación I y II de los profesores Diana Brendscheidt y Leonel De Gunther, lo que ofreció al público más que un recital de canto, un programa con ensambles de piano y dos voces de los compositores Giacomo Carissimi y Claudio Monteverdi.

En este semestre la danza también se hizo presente, primero con la coreografía de David Barrón titulada Kama los días 5 , 6 y 7 de octubre en el Teatro de la Ciudad. Dentro de la pieza vemos el vínculo que une la historia de cinco mujeres en escena. Dentro del marco de MARTesDANZA, se invitaron a distintos grupos, dando así la oportunidad al público hermosillense de conocer las distintas corrientes dancísticas. Fue así, que los alumnos/as del CEDART Hermosillo, se presentaron el 16 de octubre, con Vértigo Cantado con coreografía de Aldo Siles y We can do it de la coreógrafa Magdalena Frías, ambas 
piezas ganadoras del InterCEDART, inspiradas en dos distintos poemas donde los coreógrafos junto con los intérpretes partían de inquietud de los estudiantes de hacer danza y de comunicar con el movimiento.

El 9 de octubre se presentó la pieza A los 16, creada por Carlos Murguía, estudiante de la Licenciatura en Artes Escénicas, opción danza, siendo la primera vez que se presenta esta pieza en un foro. Es una pieza que nos hace recordar esa edad en la nos creíamos capaces de todo y, a la vez, de nada.

De vuelta al Viernes de Concierto, el 19 de octubre tuvo un programa especial con los cuatro alumnos del área de canto que ganaron las audiciones para presentarse en el Festival Alfonso Ortiz Tirado de Álamos, Sonora, el próximo año. Los alumnos Liliana Dosamantes (soprano), Daniela Chavarría (soprano), Salvador Villanueva (tenor) e Isaac Herrera (barítono), acompañados por Héctor Acosta al piano, ofrecieron un repertorio de canciones italianas y francesas, de composi-

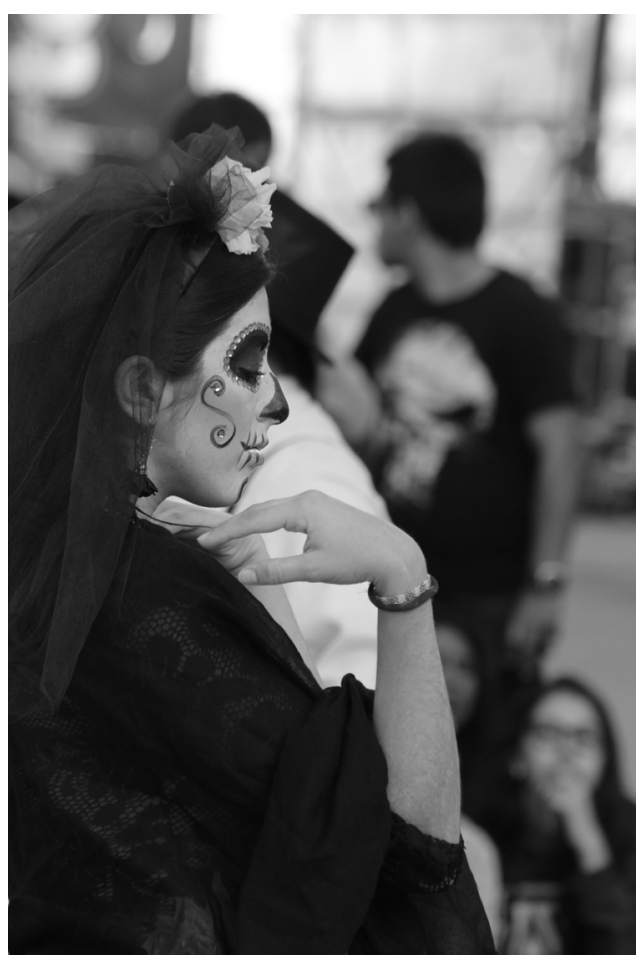

tores como Donaudy y Debussy, arias de ópera de Mozart, Verdi y Bellini, además de canción española de Torroba, canción argentina de Guastavino y cerrando el programa con canciones mexicanas de los compositores M. Armengol, María Grever, Agustín Lara y Esparza Oteo. El recital tuvo una duración aproximada de cuarenta y cinco minutos y contó con la asistencia de cuarenta y ocho personas.

El concierto ConCiencia del día 24 de octubre presentó al Dúo Quilton, formado por los guitarristas clásicos y docentes en la Licenciatura en Música Erick Quijada y Juan Díaz Hilton, quienes en 2017 decidieron conformar este ensamble con el objetivo de difundir la música de cámara para guitarra clásica. El evento contó con la asistencia de 32 personas y el programa que el dúo interpretó constó de composiciones para guitarra clásica de Luigi Bocherini, Ferdinando Carulli y Máximo Diego Pujol, así como los arreglos de canciones de "The Beattles" por Leo Brower y una pieza del compositor español Manuel de Falla.

El mes de noviembre comenzó con la tradicional procesión del día de muertos organizado por la Licenciatura de Artes Escénicas, opción actuación, el 01 de noviembre. Siete fueron los números presentados este año, añadiendo también a los estudiantes de arquitectura, haciendo de este un trabajo colectivo. Además, el Festival Catrina organizado año con año por la Licenciaturta en Artes Plásticas.

La cartelera continuó con el curso de repertorio vocal impartido por la pianista y coach vocal Teresa Rodríguez quien trabajó con el alumnado del área de canto y piano de la Licenciatura en Música, dando inicio el día 4 y terminando el curso con un concierto de clausura el 9 de noviembre. El repertorio presentado constó de canciones españolas, arias y canciones italianas de compositores como Scarlatti, Mozart y Rossini. El concierto finalizó con la famosa aria Nessun dorma de 


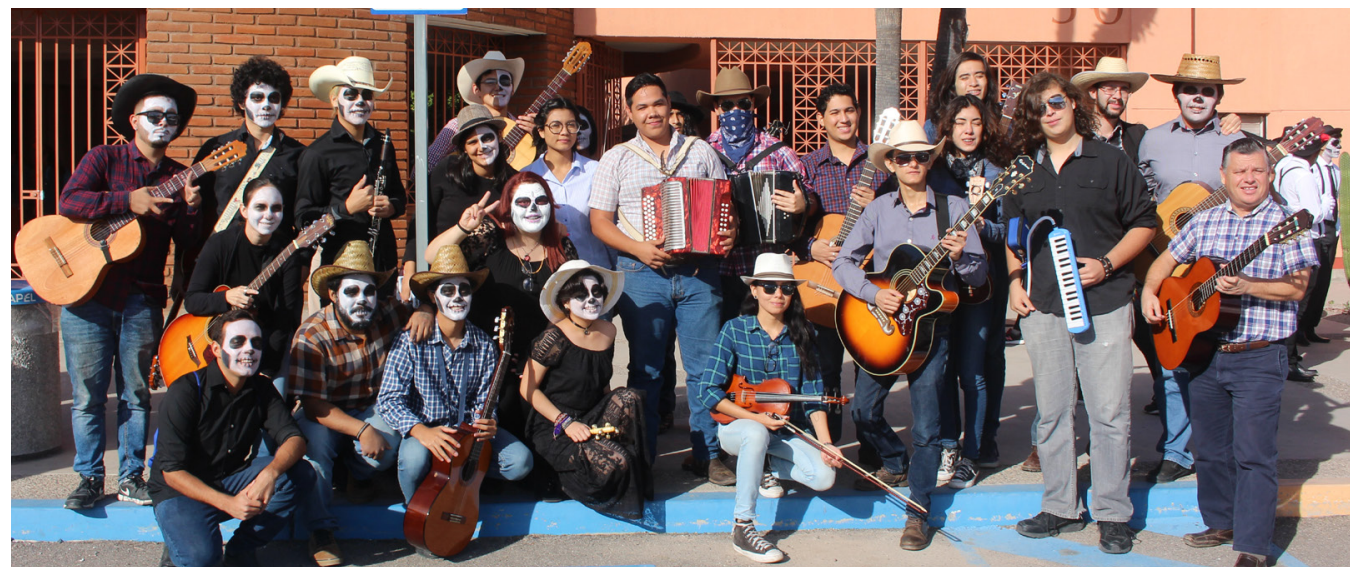

Puccini, interpretado por el tenor Ernesto Ochoa y coro dirigido por el pianista Héctor Acosta.

La compañía de danza Ceprodac fue invitada el 13 de noviembre al MARTesDANZA con el Ceprolab, un laboratorio de creación para los intérpretes de esta misma compañía que constó de 4 piezas coreográficas. El siguiente martes dió paso al primer concurso interno de interpretación coreográfica donde participaron once estudiantes de la licenciatura de Artes Escénicas, mostrando solos de su propia autoría o de personas externas exponiendo sus capacidades interpretativas. Para concluir con la cartelera de MARTesDANZA los alumnos del laboratorio de producción de la licenciatura de Artes Escénicas opción Danza, anfitriones de la temporada 2018, realizaron Fin de fiesta, donde hicieron un cierre con el recuento de todas las experiencias y todo lo vivido dentro de la temporada. La puesta en escena La H no siempre fue 8, coreografía de David Barron, fue presentada el 30 de noviembre al 2 de diciembre siendo de esta forma como concluyó la cartelera del semestre 2018-2.

La amplia variedad de eventos que nuestra universidad nos ofrece, algunos de ellos gratuitos, son una oportunidad para formar personas más sensibles al arte y como consecuencia, personas más humanas, pues eso es lo que el arte intenta expresar, emociones humanas, y las carteleras culturales que el Departamento de Bellas Artes realiza cada semestre van dirigidas no solo a la comunidad universitaria, sino al público en general. Estas puestas en escena, conciertos, exposiciones. son una gran oportunidad de pasar un momento de calidad y de apoyar al arte en Sonora.

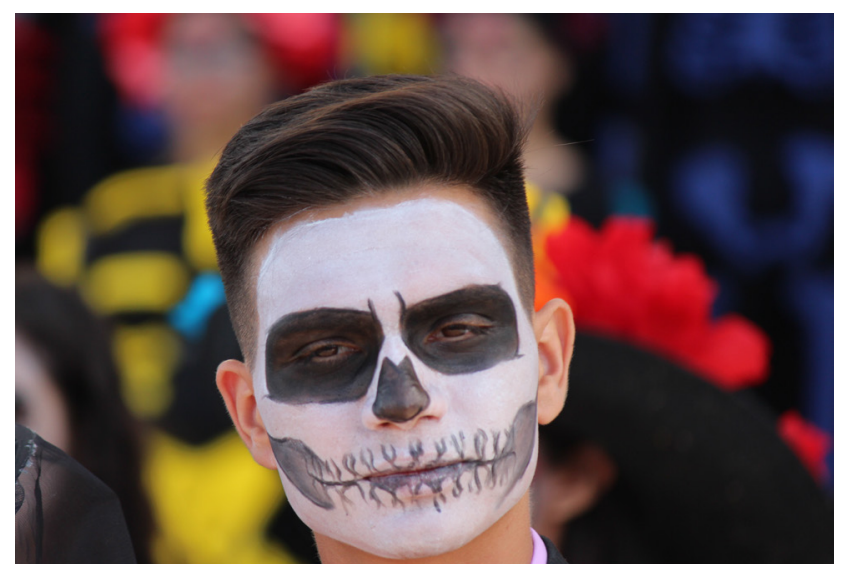

